\title{
UNA PROVINCIA "ENTERAMENTE INSULAR": GEOGRAFIA, EXPLORACIONES Y COTIDIANEIDAD EN CHILOÉ REPUBLICANO, CHILE (1826-1900)
}

MARCO ANTONIO LEON LEON*

\section{RESUMEN}

La presente investigación entrega una mirada a la historia de Chiloé durante el siglo XIX, desde la perspectiva de cómo su geografía insular modeló las formas de vida de sus habitantes y las principales características de ciudades y viviendas. Se argumenta que tal realidad fue evidenciada por los viajeros y exploradores contemporáneos que, al momento de describir e identificar las peculiaridades de este mundo isleño, hicieron notar la vinculación entre el medio y sus pobladores. Dicho reconocimiento geográfico y humano se hizo necesario no sólo para asentar la soberanía estatal-republicana en la provincia, sino además para planificar la colonización de la misma.

PALABRAS CLAVE: geografía, Chiloé, hábitat, colonización, Chile republicano.

\author{
A PROVINCE "ENTIRELY ISLAND" \\ GEOGRAPHY, EXPLORATIONS AND EVERY DAY LIFE IN CHILOÉ \\ REPUBLICAN, CHILE (1826-1900)
}

\begin{abstract}
This research provides a look at the history of Chiloé in the nineteenth century, from the perspective of how its insular geography shaped the way of life of its inhabitants and the main characteristics of cities and homes. It is argued that such a reality was evidenced by contemporary travelers and explorers, when used to describe and identify the peculiarities of this island world, noted the link between the environment and its inhabitants. This geographical and human recognition was necessary not only to seat the Republican state-sovereignty in the province, but also to plan for the colonization of the same.
\end{abstract}

KEY WORDS: geography, Chiloé, hábitat, colonization, republican Chile.

* Doctor en Historia. Académico del Departamento de Ciencias Sociales. Universidad del Bío Bío, Campus La Castilla, Chillán. Académico del Departamento de Ciencias Históricas y Sociales. Universidad de Concepción. marcoaleon@hotmail.com 


\section{INTRODUCCION}

Las impresiones actuales que se tienen sobre el archipiélago de Chiloé, evocan más bien imágenes de agrado, de contemplación armoniosa de la vida rural y marina, de bellos paisajes que se ven muy bien complementados por sus variadas y hermosas iglesias y la amabilidad de su gente. $Y$ es que la percepción que se tiene hoy en día entremezcla el interés turístico con los misterios mitológicos, una rica variedad de leyendas y una geografía que envuelve al viajero dejándole recuerdos suficientes para hacerlo volver. Se trata, en concreto, de una imagen construida por el turismo que tiende a sobredimensionar los aspectos bondadosos, relajados, naturales y románticos de la vida rural-tradicional en oposición a la agresiva, vertiginosa, artificial y deshumanizada existencia cotidiana en las grandes ciudades, como lo destaca Lowenthal (1998). Así, frente a las problemáticas urbanas contemporáneas, con diferentes ritmos de trabajo e inconvenientes de crecimiento, transporte y contaminación; se alza entonces esta imagen idílica del pasado rural chilote, como un referente identitario no sólo de lo que fue la vida isleña, sino también de lo que debiera ser en la actualidad.

No obstante, dicha construcción idealizada olvida el rescate de la evolución histórica que dice representar, pues parte del supuesto errado de que las carencias materiales de otra época conllevarian necesariamente relaciones sociales más sinceras, menos complejas y más permanentes en el tiempo. A nuestro entender, buena parte de tales simplificaciones ocurren no sólo por un desconocimiento general de la historia del archipiélago en sus diferentes períodos (colonial y republicano), sino además por una falta de profundidad en el estudio de la vida cotidiana del mismo, la cual es concebida como una continuidad que no experimenta mayores cambios, no explicándose ni el por qué de algunas de sus variaciones ni tampoco el de sus permanencias. Se olvida que el mundo insular que representa Chiloé se encuentra, como toda organización humana, marcado por logros y fracasos, expectativas y frustraciones, alegrías y fatalidades, ideas nuevas y creencias ancestrales; no contemplándose que a la vez que existía una sociabilidad estrecha forjada en torno al fogón, había asimismo una serie de dificultades mentales y materiales propias de una sociedad todavía fuertemente rural hasta avanzado el siglo XX.

Si bien la historiografía nacional ha permitido reconstruir con bastantes pormenores la historia de Chiloé, las investigaciones realizadas, por lo general, se han concentrado en el período colonial del archipiélago y en el siglo XX, como bien lo ejemplifican los trabajos de Guarda (2002), Montiel (2002), Mansilla (2008) y Urbina Burgos (2010), pero respecto del primer siglo republicano es bastante poco lo que se ha avanzado. Por tal razón, creemos pertinente entregar una mirada actual a la historia del Chiloé decimonónico mediante acercamientos que permitan una futura síntesis general, siguiendo el derrotero trazado por diversos autores como Barrientos (1997 [1948]), Darío Cavada (1914), Francisco Javier Cavada (1926) y Weber (1903).

Para facilitar el acercamiento a una temática que requiere mayores estudios y evitar simplificaciones e idealizaciones sobre un pasado chilote más deseado que real, buscamos desentrañar algunos rasgos del Chiloé decimonónico desde la perspectiva de quienes lo recorrieron, habitaron y opinaron sobre él: los viajeros. En tal sentido, esta investigación argumenta que la caracterización colonial del archipiélago de Chiloé como un mundo desarrollado a intramuros, desvinculado del núcleo histórico de Chile -como lo ha sostenido Urbina Burgos (1983)-, puede proyectarse también al siglo XIX, pues a pesar de que se sostenga oficialmente su incorporación como provincia a la república chilena en 1826, en la práctica, su condición geográfica insular y su lejanía respecto del poder central en Santiago, terminaron por reproducir y acentuar características propias de una sociedad tradicional en un período que, a nivel nacional, buscaba redefinir las relaciones entre el poder político y la sociedad civil, promover un progreso material ininterrumpido e insertar al país dentro de un modelo económico capitalista. Las singularidades de la geografía chilota, evidenciadas por exploradores, funcionarios, pobladores y colonos; cobraron relevancia no sólo por motivar a los primeros para "redescubrir" el archipiélago y hacer sentir la presencia del Estado o de sus representantes en el territorio, sino además porque permitieron constatar y explicar ante las autoridades centrales la pervivencia de un estilo de vida marcado por la tradición 
más que por el cambio, dado que si éste existía no era lo suficientemente abordado. Tal situación fue palpable, por ejemplo, al momento de describir las costumbres de sus habitantes, las ciudades y viviendas. La permanencia de ese estilo de vida, aún a principios del siglo XX, era una buena muestra de la particularidad material y humana del archipiélago, descrita por Schwarzenberg y Mutizábal (1926) e investigada por Urbina Burgos (2002). Los testimonios documentales de los contemporáneos al período aquí estudiado, nos permitirán corroborar esta impresión.

\section{RE EXPLORANDO EL TERRITORIO: UNA MIRADA CIENTÍFICA Y REPUBLICANA}

La Isla Grande de Chiloé, ubicada en la zona sur-austral del territorio de Chile, presentaba a comienzos del siglo XIX una geografía bastante particular, marcada por una suerte de espina dorsal que era una prolongación de la Cordillera de la Costa y que ocupaba su costado occidental, con cumbres superiores a mil metros y fragmentada por innumerables valles transversales. En su parte oriental, la isla contaba con una línea costera que desde el período colonial había concentrado a los principales centros poblados y, por ende, a la población blanca, mestiza e indígena de la zona. En contraste, la costa occidental que bañaba el Océano Pacífico estaba formada por acantilados y rocas escarpadas que impedían el asentamiento humano.

Dicha particularidad geográfica marcó no sólo el asentamiento de la población, sino además la relevancia de poblados como Ancud, Castro $y$, en menor grado, Chacao y Achao. Carlos de Beranger, el fundador de la ciudad de San Carlos (Ancud) a mediados del siglo XVIII, ya indicaba en su Relación Jeográfica de la provincia de Chiloé (1773) como la dispersión de la población y la complicada geografía del territorio atentaba contra el crecimiento urbano. En sus palabras, y usando de ejemplo a la ciudad de Santiago de Castro, indicaba que la

"constitución de esta ciudad por sí misma es particular, pues el concurso pende de la junta de todos los [vecinos y moradores] de sus alrededores incluso los de las islas, porque todos viven en sus estancias que se hallan dispersas en las costas, o en sus chozas, amando la soledad, de manera que semejante costumbre o sistema es verdaderamente opuesto a la sociedad y unión que debe reinar entre los hombres cultos”. Citado por Casanueva (1992, p. 9).

Tales impresiones podían hacerse extensivas a otros poblados. El temor de las autoridades españolas era que la falta de ciudades y cohesión entre los habitantes pudiera estimular el desembarco de naves enemigas, lo que permitiría que el territorio fuese fácilmente capturado. Por ello, numerosas exploraciones buscaron no sólo un mejor conocimiento del clima, el relieve y los accidentes geográficos, sino también determinar los puntos estratégicos a defender. El aislamiento de las comunidades, los problemas de comunicación entre ellas y el desconocimiento de muchos caseríos situados lejos de la costa; impedían tener un panorama cabal de la población, sus costumbres y, por qué no, sus lealtades. Desde fines de siglo la situación no se había modificado, pensándose que la pervivencia de poblaciones dispersas era una imitación fiel de las formas de vida de los primeros habitantes, o al menos esa era la explicación que entregaba el religioso franciscano fray Pedro González de Agüeros en 1791:

"Es tal lo disperso de las casas, y están los más en tales sitios, que caminando por las Islas, y aun rodeándolas por sus playas, sólo suelen verse tal qual habitación, siendo también motivo para esto que fuera de estar apartadas las unas de las otras, los ocultan los muchos y crecidos matorrales de arrayán de que están cercadas. Este modo de vivir les viene de los primeros establecimientos en ellos, el que sucesivamente se ha ido conservando y permanece". González de Agüeros (1988, 85-86).

La opinión del capitán de navío y explorador Alejandro Malaspina para la misma época no era muy distinta, entendiendo que las formas de vida estaban igualmente determinadas por la zona:

"Efectivamente la espesura del bosque que ocupa todo lo interior de la isla, no permite que se habiten sino las orillas, obligando también a abandonar las del oeste; así la mar 
muy brava, como los vientos tempestuosos que la baten continuamente. Libres de este modo los habitantes de una respiración húmeda y enfermiza, y por otra parte dueños de una comunicación fácil entre sí, o recorriendo las orillas, o transitando por canoas, han establecido su morada en pequeñas casas separadas, de modo que cada uno pueda más bien cuidar del pequeño campo que cultiva; cuidado tanto más necesario, cuanto que penden de su producto todos los recursos de la subsistencia". Citado por Sagredo y González (2004, 238).

Pese al aislamiento de numerosos poblados, que se mantuvo sin grandes variaciones después de 1826, la población era bastante significativa, pues según cálculos aproximados, a comienzos de ese siglo se estimaban en 26 mil los habitantes del archipiélago, como lo indica Vázquez de Acuña (1991-1992, p. 433). Por supuesto, durante la administración republicana el interés respecto de Chiloé ya no era de estricto carácter estratégico, pero la antes señalada dispersión iba a causar problemas al tratar de incorporar administrativa, religiosa y culturalmente la zona al resto del país.

Muchos de los visitantes de esta región, tales como cartógrafos y marinos -que venían en expediciones científicas como las de Phillip Parker King y Robert Fitz Roy- y luego funcionarios del estado chileno ${ }^{1}$, ayudaron con sus informes y escritos a tener un mejor conocimiento de las islas, sus habitantes, modos de vida y las dificultades del día a día que afectaban tanto a los intendentes como al más modesto de los pobladores, según lo ha examinado Mansilla (2005). Todos, en mayor o menor medi$\mathrm{da}$, se refirieron a los inconvenientes del aislamiento de no pocas comunidades debido, en gran parte, a terrenos accidentados y a una abundante vegetación que era prácticamente desconocida, además de impenetrable. Fue a través de sus experiencias que se "redescubrió" Chiloé insular y continental a los ojos republicanos, permitiéndose evaluar las desventajas de su geografía, el clima y las comuni-

1 Entre los primeros trabajos de exploración y reconocimiento científico por parte del Estado chileno, pueden mencionarse el del bergatín goleta Janequeo en 1857 , cuyos jefes y oficiales realizaron el plano de los canales de Dalcahue y Quinchao, del archipiélago de los Chonos y el de la península y archipiélago de Taitao. El de puerto caciones de este mundo desarrollado a intramuros "en contacto estrecho con los indios domésticos, pero casi desvinculado del núcleo histórico". Como lo expresa Urbina Burgos (1983, p. 16).

Un gran inconveniente eran las comunicaciones, pues los bosques, barrancos y las costas accidentadas, no permitían un fácil tránsito. Casi no existía un sector de la Isla Grande que no tuviese una densa selva, pues la costa occidental y las montañas de ese lado se perdían bajo el impenetrable manto arbóreo. Hacia la costa oriental, que concentraba la población, también espesos bosques de alerces, ulmos, cipreses, avellanos, canelos y robles dificultaban la comunicación con el interior, aparte de que los fuertes vientos de "travesía", que corrían de mar a cordillera, impedían la construcción de puertos. Una planta común, la quila, una suerte de bambú que se entrecruzaba en forma impenetrable, dificultaba la tala de árboles, convirtiéndolos en obstáculos para el avance de caminos desde la costa. Si a ello agregamos factores como la lluvia, el viento y los temporales, que por lo normal borraban senderos aparte de dejarlos convertidos en lodazales; tendremos una idea aproximada de lo complicado que era para los lugareños internarse en algunos sectores. Frente a este panorama, la mejor salida fue la vía marítima que comunicaba a puertos y caletas, como bien lo destacaba el viajero Carlos García Huidobro a mediados de siglo:

"Una navegación por las costas de Chiloé, o por el interior como dicen, es uno de los paseos más agradables con que se puede recrear una persona poco acostumbrada al regalo i a las comodidades que presentan las poblaciones; aquí encontramos alhago para todos los caracteres, i sobre todo las bellezas naturales que tenemos a nuestra vista a cada paso. Apenas se sale del canal de Chacao, estendemos la vista por el golfo de Ancud, en cuya ribera oriental se marcan deteniendo nuestra vista los majestuosos picos de la cordillera, que lucen sus nevadas

Low en las Guaitecas, fue levantado por el guardia marina Aureliano Sánchez en 1858. El mapa de los canales de Chacao, Calbuco y del seno de Reloncaví fue levantado ese mismo año de 1858 por Javier Barahona. El de la dársena de Huite fue hecho a bordo del vapor Maipú en 1862 . 
cumbres cortadas en mil caprichosas formas. Vemos allí alzarse impávido al volcán Osorno, los picos jemelos del gran Calbuco, más al sur el Chayapireu o Minchiumávida i el singular Corcovado; tras de estos se estiende como una faja dentada el cordon de la cordillera; que con la trasparencia atmosférica se nos aparece azulada, alternando con las planchas de hielos eternos que las coronan. A sus pies se divisan con un anteojo los elevados i blanquecinos tallos de alerces, sombreando con sus bellos copos las plantas que vejetan a sus pies" (1864, p. 462).

Una vegetación exuberante, producto de una lluvia incesante durante casi todas las estaciones del año, se encontraba presente a lo largo y ancho de la Isla Grande, siendo los espacios "civilizados" o "domesticados" ínfimos. Estos se concentraban en torno a los centros urbanos y sus alrededores, pero a medida que el visitante se alejaba de ellos el paisaje natural cobraba todo su esplendor. En las islas del interior, descritas muy escasamente, era posible imaginar que la situación fuese más extrema, con caseríos dispersos, separados por grandes distancias, escasa comunicación en el invierno y un poco más frecuente en el verano. La impresión de quienes realizaban oficialmente la descripción de la provincia no era muy diferente. De hecho, en la presentación que se hizo de la zona para la publicación del Censo de Población de 1875, se indicaba que islas como Acui, Alao, Anihue, Apiao, Aulen, Butachauques, Caguach, Chailin, Chaulinec, Chauques, Cheniao, Coleto, Cochinos, Caucahue, Chaulin, Chelín, Chuid, Doña Sebastiana, Guafo, Lacar, Lilihuapi, Lemuy, Linlin, Llahuenhuapi, Llinua, Meulin, Melinka, Quehui, Quilan, Quenac, Quinchao, San Pedro, Tac, Talcan, Tranqui, Trenquelin, entre otras; estaban

"cubiertas de espesos montes que apenas dejan terrenos despejados para el cultivo. Debido a esta circunstancia i a los numerosos canales que separan las islas, bordadas de vegetación i formando mil caprichosos jiros, ofrece la provincia el aspecto de una naturaleza virjen i hermosísima" ("Provincia de Chiloé", en Quinto Censo Jeneral de la población de Chile, 1876, p. 15).
Aunque el mar era el principal medio de transporte y comunicación, era preciso también llegar a otras zonas no cercanas a la costa o a los ríos. En tierra, el tránsito a caballo o a pie debía hacerse en las condiciones antes descritas, sorteando el barro y las irregularidades de los terrenos. No obstante, existían desde fines del período colonial algunas alternativas que prestarían utilidad para el resto del siglo XIX. Tal era el caso del camino entablado de Quirquerque, que conectaba a San Antonio de Chacao y Calen, el cual estaba cubierto con tablones para evitar la formación de barro. Asimismo, desde 1788 se había empezado a utilizar el denominado camino de Caicumeo, nombre dado en recuerdo de un indígena que lo había trazado a través del bosque, se decía, empleando sólo un machete. La ruta unía las ciudades de Ancud y Castro, aunque quienes se atrevían a ocuparlo debían tener en cuenta que se cruzaban terrenos pantanosos, lo que provocaba que fuese constantemente reparado. Según un relato contemporáneo, el camino estaba compuesto

"de tablones de un pie de ancho por tres o cuatro pulgadas de grosor, i de largo variable, generalmente de seis a ocho varas; se estienden estos sobre unos trozos de maderas, que sostienen dos postes cortos enterrados en la tierra, generalmente un fango espeso; en las quebradas profundas i en los rios se sigue el mismo sistema, solamente que los postes clavados son entonces mas altos, dejando pasar el agua mui por debajo. Cuando se pasa por estos puentes a caballo i al gran trote, como siempre se anda por allí, si miramos para adelante los vemos ondularse i oscilar, pero son bastantes fuertes para resistir el peso de un caballo. A un lado i otro del camino queda un espacio bastante ancho que en el verano, cuando las lluvias han sido escasas, está seco i se puede pasar por él sin el menor peligro; pero en la parte que llaman el sendero, que son como cinco o seis leguas, este espacio es pantanoso, la montaña se aproxima mas al camino i queda como un callejón con sus altísimas murallas, en donde asientan los rayos solares de un modo sofocante. La impenetrabilidad de la montaña i las curbas del camino, impiden que corra alguna fresca brisa, ademas la cantidad de tábanos que asaltan al viajero aumentan su sofocación, fati- 
gándolo extremadamente".

García Huidobro (1864, p. 466). Para una descripción anterior, véase Darwin (1995, p. 180).

La acumulación de lodo, piedras y los desniveles del terreno convertían a los tablones en una especie de puente colgante que causaba más de una caída a quienes se atrevian a transitarlo. Por lo menos una vez al año los chilotes debían encargarse de su reparación, sin recibir remuneración alguna. Esta forma de acondicionar caminos con tablones se llamaba "planchado", y consistía en colocar troncos de madera de dos metros de largo, por lo general, transversalmente uno al lado de otro al modo de los durmientes de un ferrocarril, pero que estuviesen tocándose, siendo sus contornos naturales redondeados. En algunos lugares incluso se labraba la cara superior de éstos. De este modo se llenaban las partes pantanosas o fangosas de muchas sendas, permitiendo el tránsito de personas, caballos, carretas y de canoas sin ruedas que se arrastraban sobre los maderos.

Uno de los testigos de los intransitables caminos de Chiloé, fue el naturalista Charles Darwin, quien al llegar a la Isla Grande, en noviembre de 1834, se impresionaba por el mal estado de éstos, situación que experimentaría pocos avances. Casi un siglo después, otro visitante de la Isla Grande, el capitán de fragata Arturo Whiteside, expresaría con molestia e ironía que las

"vías de comunicación por tierra existen sólo en el nombre i apenas son viables para cabalgaduras i jente de a pie. El que conozca los caminos del centro de Chile en el invierno i considere lo que serían esos caminos si se les agregase gradientes de 15 a 30\%, podrá formarse una idea de lo que son los caminos por la playa siempre que les es posible.

De estos pseudo caminos, salen de Ancud dos: uno corto que conduce a Linao, en la costa oriental i el otro, llamado de Caicumeo, que conduce a Castro.

La construcción de ferrocarriles en Chiloé no es aún necesaria i creo que pasarán muchos años antes que lo sea; en cambio la vía marítima, más económica, aunque un poco más larga, está espedita" (1900, p. 112).

Aunque parezca pintoresco señalarlo, los inconvenientes del clima, el terreno y la incomunicación a veces encontraban su contraparte en el exuberante y maravilloso escenario de bosques vírgenes y maleza que rodeaba a los intrépidos que se aventuraban a internarse en su espesura. El propio Darwin destacaba como "un gran número de árboles siempre verdes y de plantas de carácter tropical reemplazan aquí las sombrías y tristes hayas de las costas meridionales. En invierno el clima es detestable: por lo demás, no es mucho mejor en verano. Creo que hay pocos lugares en las regiones templadas del mundo donde llueva más. El viento sopla de continuo tempestuoso, y el cielo está siempre cubierto; una semana completa de buen tiempo es casi un milagro" (1995, p. 153). Y el naturalista inglés no exageraba, pues la Isla Grande y otras islas menores se encontraban casi todo el año expuestas al soplo de los vientos húmedos del oeste y noroeste, lo que provocaba veranos frescos e inviernos con mucha lluvia y humedad, en especial durante los meses de junio, julio y agosto en que podía llover por 15 días y más. Según el reconocimiento de Pedro Lucio Cuadra, las lluvias daban vida "a una vegetación robusta i elegante que nada tiene que envidiar a las mas nombradas de los países tropicales. La espesísima vegetación de esta comarca parece comprimida por sí misma, i sus corpulentos árboles se elevan a porfía sobre el horizonte hasta tanto que puedan presentar sus robustos i matizados copos a la benéfica influencia de los rayos solares" (1866, p. 271). Un estudio realizado por el comandante Roberto Maldonado a fines de siglo, indicaba que el número anual de días de lluvia en todo el archipiélago era de 197 (1897, p. 203), lo que podía, por supuesto, aumentar en determinados períodos.

\section{POBLADORES Y COLONOS: UNA DIFÍCIL CONVIVENCIA CON EL ENTORNO}

El desconocimiento de la geografía chilota era preocupante para las autoridades chilenas, pues ello no sólo implicaba inconvenientes administrativos y de control efectivo de los habitantes, sino un mal panorama para impulsar una posible 
colonización. Relación entre territorio y población que ha sido bien estudiada para otros escenarios geográficos por Fraile y Bonastra (2001). Ya en el Ensayo sobre Chile, escrito por Vicente Pérez Rosales y publicado en Francia en 1857, se dejaba constancia de que Chiloé insular y continental, rodeado al este por la cadena montañosa de los Andes, era virtualmente inexplorado "porque no obstante el considerable número de trabajadores que se dirigen alli en la primavera, sus informes sobre esta comarca desierta son muy contradictorios y no concuerdan más que en un solo punto y es, que la cadena de los Andes pierde su continuidad en muchas partes de estas latitudes, o al menos su línea culminante experimenta allí descensos tan considerables, que se puede pasar a la Patagonia oriental sin hacer una ascensión sensible". Respecto del archipiélago, los juicios eran similares, indicándose que "no podemos decir nada sobre el interior de las tierras de la provincia de Chiloé. No ha sido visitada, porque es literalmente imposible, sin trabajos preparatorios y dispendiosos, penetrar al través de las inmensas selvas vírgenes que cubren el suelo. Casi toda la población está alineada a lo largo de las costas de las islas, en una zona de menos de una milla de ancho, término medio; y las necesidades de una agricultura descuidada siendo ampliamente satisfechas por el poco terreno que el hacha y el fuego han puesto a su disposición en los linderos de los bosques, no se han dado el trabajo de visitar el resto de la comarca" (1986, p. 185 y 186). La excepción a este panorama eran las islas de Quinchao y Lemuy, cuyos bosques habían sido talados y sus tierras empleadas para la agricultura. Para fines de nuestro período se estimularía la colonización por extranjeros, la misma que promovería Maldonado en su escrito y que se materializaría a mediados de la década de 1890 con la llegada de 620 familias a la Isla Grande (1897, p. 177).

Avanzado el siglo, algunos progresos se habían hecho, pero aún era evidente el contraste entre el dominio de la naturaleza y el del hombre. Las ciudades mantenían una fisonomía más bien rural, como lo indicaba la narración de Carlos García Huidobro, quien se sorprendía en 1864 de las

"formas de los vejetales, los caprichos de sus contornos, adornado el paisaje con flores de varios matices, que resaltan en el verde paño del cerro i en fin vemos tan pintoresca i variada nuestra vista real de ayer, que casi nos ponemos a dudar de su existencia. Bajo esta influencia se llega a Ancud, i como aquí las bellezas de la naturaleza salvaje se hallan reemplazadas por la esmerada simetría de la cultura humana nos disipa nuestra ilusión para volvernos a nuestro ser i al estado social admiramos aquí el contraste de la confusión con la naturaleza, con el prolijo esmero del hombre; el contraste de la vida libre en su desarrollo, con la forzada organización bajo su mano [...] Este contraste se nos realza mucho más en Ancud, en donde se nos aparecen los alineados zurcos de batatas, como un lienzo ondulado por las desigualdades del terreno, i tras ellos, i a nuestro alrededor vemos alzarse una vigorosa vegetación confusa por la distancia" (1864, p. 451-452). Ver también Lucio Cuadra (1866, p. 266-276).

Las condiciones geográficas reseñadas determinaban un modo de vida bastante peculiar, en el cual el contacto con la naturaleza era estrecho. Los viajes de exploración y reconocimiento científico, ya fuesen de particulares o de agentes del gobierno, se percataron de lo mismo, haciendo notar los cambios que el paisaje había experimentado, como indicó Marin en su estudio (1881, p. 75-95). En 1871, Carlos Juliet, ayudante de la comisión exploradora de las costas de Llanquihue y Chiloé, registraba que

"actualmente se verifica un hundimiento, al menos en ciertos puntos, del archipiélago de Chiloé; así en la isla Huar, me referían unos labradores que en tiempos de sus padres sembraban una extensión plana de terreno que ahora cubren completamente las grandes mareas" (1871, p. 122).

De seguro esta no debió ser la única variación, pero las geografías oficiales describían más bien lo que era evidente a la vista de cualquier observador, destacando las virtudes de los lugares y no los posibles inconvenientes. La Jeografía descriptiva de la República de Chile de Enrique Espinoza, cuya primera edición apareció en 1890 , era más cauta al caracterizar a Chiloé, pues aparte de destacar sus atributos, hacía notar algunos de 
sus problemas, los cuales se hacían derivar de su condición de provincia "enteramente insular", en la cual "la mayor parte de las islas que la componen se encuentran cubiertas de espesos bosques i separadas entre sí por estrechos canales, que en parte dificultan la navegación a causa de las rocas de que están sembrados". A ello debía sumarse el que "las vías de comunicación terrestre son escasas i de malas condiciones" (1897, p. 436-437). Como se puede apreciar, en este aspecto no hubo grandes avances desde los inicios de la administración republicana, lo que despertó críticas hacia quienes, desde el gobierno central en Santiago, promovían la colonización de la provincia. Fue en la década final del siglo XIX cuando las falencias antes anotadas (mal clima, irregularidad en los terrenos, falta de medios de comunicación y permanencia de bosques impenetrables que no favorecían la agricultura) se hicieron notar con más fuerza.

Uno de los críticos del proyecto colonizador, Belisario García, indicaba la indefensión en que habían quedado varias familias de colonos en un entorno mal conocido y complicado desde todo punto de vista, en particular porque los terrenos habían sido asignados por personeros de la Oficina de Inmigración que no tenían ningún conocimiento de la zona: "si lo elemental en toda empresa de colonización es la viabilidad, es indudable que salta a la vista la necesidad que hai de escojer para la ejecución de esta clase de esplotaciones terrenos sin bosques impenetrables, en los cuales sea fácil la tarea del desmonte i de la delimitacion o hijuelacion [...] Estando ubicados los establecimientos de colonización en parajes boscosos, lo natural es que los caminos construidos para los efectos de la comunicación entre los diversos establecimientos i la capital de la provincia, desaparezcan con la rapidez del relámpago tan pronto como empiezan las grandes lluvias" (1899:344).

En tales condiciones, alemanes, argentinos, austriacos, belgas, brasileños, españoles, franceses, holandeses, ingleses, italianos, rusos, suecos y suizos; enfrentarían el desafío de colonizar, aún a fines de la centuria decimonónica, un territorio en gran medida inexplorado. Dicha colonización tomó lugar entre los meses de noviembre a diciembre de 1895 y enero de 1896, principalmente, según consta en el informe de Vega (1896). Los colonos fueron instalados en Chacao, Pumanzano, Camino Nuevo, Laja Blanca,
Mechaico y Quetalmahue. Allí se destacó un grupo compuesto por 85 familias británicas que llegó a ser conocido como la colonia escocesa, el que se ubicó no lejos de Ancud, en el extremo norte de la Isla Grande en una zona llamada Huillinco, descrita por Gilchrist (1981). Se prefirió el departamento de Ancud al de Castro, a pesar de que había quienes opinaban que los terrenos de este último eran más aptos para la agricultura, lo que sin duda fue relevante al momento de explicar gran parte del fracaso del proyecto como lo explicó Weber (1903, p. 153). Al juicio de Belisario García, el territorio más apropiado para una colonización era cerca de Quellón, pues los

"terrenos que hai en esta parte de la Isla Grande son inmensamente mejores en calidad vejetal, que los que existen en las demas rejiones de la Isla; de modo que se puede decir, sin faltar a la verdad, que toda empresa de colonización debe tener asiento natural en el lado sur del archipiélago, i no en el lado norte como se ha hecho" (1899, p. 371).

Si bien el diagnóstico fue negativo, pues, según García, de las 265 familias de colonos para 1899 la mitad había desaparecido o salido de Chiloé "a causa del mal tratamiento, de la dureza del clima i de la ninguna probabilidad que tenían de poder prosperar en la isla" (1899), no es menos cierto que muchos se quedaron y otros siguieron llegando durante el nuevo siglo. Una buena parte de los escoceses también se retiró quedando en Huillinco sólo 12 de las 85 familias originales para inicios del siglo XX. Pese a contratiempos como la dureza del clima, el extravío de algunos colonos en los bosques, el sortear caminos convertidos en pantanos durante el invierno, la falta de tierras cultivables, de viviendas dignas, de condiciones laborales, de salud y de provisiones, entre otros aspectos; muchos de ellos supieron poco a poco mejorar sus condiciones de vida. Al igual que el resto de los habitantes de Chiloé, pudieron sobreponerse a las adversidades y salir adelante proyectando un ejemplo a sus descendientes, como fue retratado por Mc Bride (1938, p. 291-298).

Caso muy diferente fue el desplazamiento de chilotes hacia los canales australes, no con fines de reconocimiento geográfico ni de colonización, sino más bien para explotar los recursos naturales de la zona tales como el guano, el aceite y los 
cueros de lobos marinos; productos que generaron un comercio considerable y un asentamiento espontáneo y temporal en la actual región de Aysén, como bien lo ha estudiado Martinic (2005:111116). La evaluación que se ha hecho de esta etapa de la historia de Chiloé, por parte de Emperaire (2002, 101 y ss), no ha sido positiva, en particular por la acción de loberos y hacheros chilotes, cuyas actividades extractivas afectaron significativamente a la población autóctona, al número de mamíferos marinos y a especies arbóreas como el ciprés. Entendemos que dicha temática es más compleja que lo expuesto y que se ha avanzado en la materia con investigaciones como las de María Ximena Urbina sobre la explotación del ciprés (2011), pero no es menos cierto que la documentación de época refuerza estereotipos. Por ejemplo, en 1867, las palabras del subdelegado del archipiélago de las Guaitecas y fundador de Melinka, Felipe Westhoff, resumían una percepción que no era aislada:

"En el último verano el Archipiélago de los Chonos ha sido poblado accidentalmente por cerca de tres mil peones ocupados en la corta de madera y en la preparación. Esta cantidad de gente ha sido ocasión de violencia, tropelías, asesinatos y otros crímenes que la autoridad no ha podido evitar por falta de fuerza armada a su disposición.

Esa misma cantidad de peones, sin sujeción, sin Dios ni ley, puede decirse, y sin nada que les impida llevar adelante sus caprichos o sus fechorías, incendian los bosques en donde quiera les de la gana o inutilizaban de esa manera una gran cantidad de madera..." (1867, p. 445-474).

La falta de una fiscalización oportuna, las difíciles condiciones geográficas, así como la actitud asumida por las autoridades centrales de dirigir su interés hacia los territorios del norte del país, entre otras razones, provocaron un daño irreparable. De hecho, Luis Carreño Palma (1997, p. 93102), ha hecho notar cómo entre 1880 y 1930 se produjeron efectos, no sólo en el ecosistema, sino además en la población kawéshkar que allí habitaba. De acuerdo con la reconstrucción oral realizada por Joseph Emperaire (2002) entre los descendientes de los indígenas, las expediciones de caza de los chilotes duraban casi siempre de tres a seis meses y aún más, pues era fácil traspasar los límites legales de cacerías en territorios mal vigilados. Los barcos y goletas en que llegaban los cazadores se dispersaban por los archipiélagos, cerca de los roqueríos donde se encontraban las focas, formando cuadrillas compuestas de una chalupa y seis hombres que se dedicaban a matar y despojar a estos animales de sus crías y pieles. Se establecieron campamentos que eran visitados por dichas goletas, los cuales eran aprovisionados al final de las faenas con pieles de focas cuidadosamente descarnadas, saladas y colocadas en toneles.

Kawéshkar y chilotes tuvieron en principio recelos, pero al poco tiempo los aborígenes entraron en confianza gracias a pequeños regalos, brindándoles finalmente a los isleños mano de obra diestra y gratuita. "A cambio de su trabajo de preparación de pieles, recibían alimentación chilota, galletas de harina, papas, cebollas y café de higos. A cambio de sus pieles de nutria y de coipu, recibían ponchos y frazadas de valor y calidad mucho menores". Pero no todo fue un amistoso intercambio, pues los

"loberos manifestaban un vivo interés por las mujeres alacalufes. Los raptos de mujeres y muchachas, y aún de muchachos para hacerlos marineros, eran frecuentes. Es fácil suponer que tales hechos no se producían sin violencias. Un número considerable de alacalufes fueron así transplantados a Chiloé, Puerto Montt y Punta Arenas" (2002, p. 102).

Este fue un triste episodio en la historia de esta expansión chilota, muestra de que las ambiciones y deseos de ganancias rápidas desde antaño provocaron repercusiones que sólo en el presente hemos evaluado con un poco más de criterio. Sin embargo, este tema merece aún mayores investigaciones $-y$ matices- que permitan ponderar las repercusiones sociales y culturales de esta actividad en una zona donde la soberanía chilena era muy débil o francamente inexistente.

\section{EL HÁBITAT CHILOTE: CIUDADES Y VIVIENDAS}

Durante el siglo XIX las pautas de vida 
chilotas no fueron muy distintas a las que existieron durante los siglos coloniales. La mayor parte de la población vivía en aldeas, caseríos o propiedades pertenecientes a una sola familia. Observadas desde la costa, cada una de estas concentraciones humanas se componía de una iglesia, una escuela y media docena de casas al borde del agua, pues, como se dijo, para trasladarse de un punto a otro el mar prestaba una vital utilidad, aparte de que la playa también permitía el desplazamiento a pie y a caballo, en especial durante la bajamar, ya que muchos pasos se inundaban haciendo imposible el tránsito. Si era preciso transportar alimentos para venderlos en el mercado de alguna ciudad, como San Carlos de Ancud o Castro, o traer provisiones desde allí, debiendo pasar obligadamente por tierra, no era extraño ver cómo los campesinos confeccionaban y trasladaban canoas que, arrastradas sobre el barro, permitían llevar carga bastante pesada entre trayectos considerables a modo de una carreta con bueyes. Esos maderos cavados eran los llamados dornajos de tira, usados igualmente sobre los planchados. Por tales razones abundaban en las playas estas canoas aptas para usos terrestres y marítimos, fiel reflejo, entre otras cosas, de esa cultura bordemar que definía la especial relación de los chilotes con la tierra y el mar. Esa es la imagen entregada desde mediados del siglo por García Huidobro (1864), Martin (1881) y Maldonado (1897).

Las casas eran de madera con un techo elevado y con pendiente para facilitar el descenso de las aguas, siendo los costados recubiertos de tejuelas de alerce, aunque en los villorrios, o a orillas de los canales y los ríos, también se usaba el ciprés o mañihue, según lo expresan las descripciones de los viajeros aquí citados. Al lado de estas viviendas se ubicaba el chiquero, donde se criaban los cerdos, el caldizo, en el cual se encerraban las ovejas y el campanario, que servía para guardar las cosechas. Todo ello en medio de un pequeño predio rodeado por una cerca, también de madera, dentro de la cual se movían con suficiente holgura cerdos, vacunos y caballos. Quienes no optaban por la madera vivían en ranchos. La piedra y el ladrillo tenían poco uso, de modo que el aspecto general de los centros poblados reflejaba a su vez la principal industria de los habitantes. Los cercos eran construidos con estacas que sostenían hileras de tablas o trozos de troncos enterrados en el suelo con una baja y maciza empalizada. Frente a las casas, en dirección a la playa, una reja circular se internaba en el agua, a modo de trampa, para atrapar a los peces que allí se depositaban a la hora de la marea baja. Estos eran los corrales de pesca, los mismos que Charles Darwin había divisado en su visita a la isla de Lemuy (1995, p. 160). Detrás de las habitaciones, se encontraban las siembras de papas y granos que ocupaban las tierras descampadas y, más allá, estaba el bosque que cerraba toda comunicación con el mundo en esa dirección, pues sus extremos se prolongaban a uno y otro lado del caserío y de las propiedades individuales, hasta tocar los bordes del mar. El paisaje estaba asimismo salpicado por granjas con modestas casitas rodeadas por un jardín y una verja que circundaba el pequeño campo adyacente. Los escasos despejes de terreno eran producto de un infructuoso trabajo que había implicado horas y horas de lucha contra matorrales, arbustos y árboles de gruesos troncos. Salvo tales espacios ocupados por el hombre, la selva austral descendía compacta hacia la costa. Como se comprenderá, en tal escenario los terrenos agrícolas eran muy limitados y nunca alcanzaban las cinco o seis millas hacia el interior, a no ser en los márgenes del camino de Caicumeo, pero sólo como una excepción.

La perspectiva entregada por el franciscano Agüeros a fines del siglo XVIII, no era muy diferente del panorama que podía evidenciarse en muchos lugares del archipiélago aún avanzado el siglo XIX. Según este religioso, las viviendas de los pobladores, por lo común, eran

"unos mal formados ranchos de palos y tablas: pero tal disposición los mas, que para tapar las junturas y huecos que median entre ellos, se valen de pedazos de pellejos de carnero, y trapos viejos. Los techos son de paja, y es forzoso renovarlos con freqüencia para evitar el que los pasen las aguas. Luego que se entra del umbral de la puerta para dentro está a la vista toda la casa con quanto en ella tienen, y allí se hallan tambien las gallinas, y otros animales domésticos. Son muy raras la casas que en su puerta tienen cerradura y llave, y en lugar de esto usan unas tranquillas, diversas unas de otras, pero muy seguras. Aquellos que tienen 
mayor posibilidad hacen sus casas, aunque de madera, con todas las habitaciones necesarias, y en quanto pueden abrigadas, forrándolas por dentro con tablas bien unidas, techándolas con las mismas, y su piso es de tablones de laurel. El techo en la disposición que estos le ponen con las tablas, no da lugar a una gotera, y es de mucha duración" (1988, p. 111-112).

En poblados de mayor envergadura la situación no era distinta, pues la precariedad era una característica que había marcado al archipiélago desde temprano. Las ciudades como Ancud y Castro tenían casas construidas exclusivamente de madera y con techo de tejuelas, cubriéndose incluso las aceras de las calles con gruesos tablones para evitar el barro y el polvo. Las viviendas que se consideraban más acomodadas, lo eran en función de su tamaño y no tanto por su lujo o decorado. En 1826, la casa del vecino Ricardo López, dueño de la chacra de San Antonio, ubicada a tres leguas de la ciudad de Ancud, era descrita por su hijo de la siguiente manera:

"La casa de mis padres, como todas las habitaciones rústicas del Archipiélago, se componía de una sala grande, que hacia las veces de salón, de pieza de recibo y de comedor, y cuando había alojados servía también de dormitorio. Las camas se instalaban sobre los largos estrados que rodeaban casi los cuatros costados de la sala; estos estrados estaban cubiertos por tejidos multicolores de lana, semejantes a frazadas, y contaban además con una media docena de cojines o almohadones de lana, con sus blancos añascados y miñaques hechos por mis hermanas. Este salón comedor tenía dos puertas que llevaban al dormitorio de mis padres y al de mis hermanas; el nuestro estaba aparte en una mediagua que se apoyaba en el costado norte de la casa. Al lado sur estaba el gallinero y el chiquero y en el costado de la travesía se levantaba la cocina, dividida en dos secciones, una ocupada por ésta, con su fogón central y la otra hacía de pesebrera, y separadas ambas por un tabique de doble forro" . Citado por Darío Cavada (1945, p. 200-201).

La pobreza de la población y su aspecto influían al momento de emitirse opiniones sobre la ciudad, pues el uso de la madera podía tener ventajas en la zona por su fácil acceso y costo, aunque era un dolor de cabeza al momento de enfrentar tragedias como los incendios, fruto de descuidos humanos y avivados por las cambiantes corrientes de aire y los fuertes vientos. Las secuelas de uno de esos siniestros, fue lo que pudo evaluar el teniente ruso N. Fesun en su llegada a Ancud en 1861, describiendo a la localidad como

"enteramente compuesta por pequeñas casitas de madera; [lo que] desde lejos hace recordar Petropavlovsk en Kamchatka. Hace varios años la ciudad fue exterminada por un incendio, sus habitantes en general no son ricos, razón por la cual la reconstrucción ha sido bastante lenta, y en su aspecto actual no es atractiva. [...] los habitantes de la ciudad asombran por su flojera y desaseo; entre la plebe hay muchos tipos de indios mezclados con chilenos. Cuando en la rada no hay barcos comerciales que requieren de mano de obra para carga y descarga, en las calles hay durante el día entero, especialmente en las tardes, música y bailes; la ebriedad es muy común. La clase alta se dedica al keif [ocio], a los chismes, al agua con hielo y azúcar (con el último ingrediente en casos extremadamente solemnes), y a la inevitable zamacueca, el baile nacional chileno. [...] En San Carlos se puede conseguir agua dulce, leña y aves por precios muy bajos, y a veces, frutos del mar, en cantidades pequeñas. No tienen almacenes de carbón permanente; conseguimos 30 toneladas que había dejado por casualidad uno de los buques militares chilenos, y sólo gracias a la amabilidad especial del gobernador o del intendente de la provincia, según declara su título oficial" (2000, p. 423-424).

Los centros poblados más significativos, como se adelantó, eran San Carlos de Ancud, capital de la provincia desde 1834 y sede del obispado; Castro, capital del departamento del mismo nombre; y Achao, capital del departamento de Quinchao. Cierta cantidad de población, aunque no de manera permanente, pues estos lugares sólo cobraban vida en determinados momentos del año, 
se concentraba en caseríos como Tenáun, Chacao, Lliuco, Quemchi, Quicaví, Dalcahue, Curaco, Chonchi, Puqueldón, Quinchao, San Javier y Quenac. Los puertos más frecuentados eran los de San Carlos y Chacao, al norte de la Isla Grande; y Dalcahue y Castro en la costa este de la misma isla. Respecto del actual poblado de Queilen, debe decirse que por mucho tiempo su denominación fue imprecisa, pues la puntilla donde se ubicaba fue conocida coloquialmente como el "comedio de los payos", pero a partir de las décadas de 1870 y 1880 se optó por usar su nombre veliche que significaba rabo o cola. No obstante, al momento de habilitarla como puerto menor, un decreto del Presidente José Manuel Balmaceda estableció que debía llamarse Puerto Grille en recuerdo del capitán español Cipriano Antonio de Grille y López de Haro. Tal situación "no fue asimilada por la población y sin quererlo el decreto del presidente Balmaceda logró lo que los años de uso no habían conseguido: unificar la denominación del poblado bajo el título de Queilen", como indica Larrocau en su investigación (2000, p. 54).

La precariedad y la carencia de una imagen de ciudad fueron hechas notar desde temprano por autoridades y viajeros. Darwin sólo decía escuetamente que la aldea de Chacao había sido "en otros tiempos el principal puerto de la isla, pero habiéndose perdido un gran número de barcos a causa de las peligrosas corrientes y de los numerosos escollos que se encuentran en los pasos, el Gobierno español hizo incendiar la iglesia y así arbitrariamente obligó al mayor número de habitantes de ese pueblo a trasladarse a San Carlos". Sobre Castro la impresión no mejoraba, pues allí aún se veían

"los rastros del plano cuadrangular común de las ciudades españolas; pero las calles y la plaza están en la actualidad recubiertas de una espesa capa de césped que ramonean los carneros. La iglesia, situada en el centro de la población, se halla completamente construida de madera y no carece ni de aspecto pintoresco ni de majestad. El hecho de que uno de nuestros hombres no pudo lograr adquirir en Castro ni una libra de azúcar ni un cuchillo ordinario dará una débil idea de la pobreza de esa ciudad, aunque viven aún en ella algunos centenares de personas. Ninguno de ellos posee ni reloj de bolsillo ni péndulo, y un anciano, que tiene fama de calcular bien el tiempo, da las horas con la campana de la iglesia en absoluto cuando a él le place" (1995, p. 155 y 159).

Hacia finales del siglo la fisonomía de las ciudades no había cambiado significativamente. Gracias a la información proporcionada por el censo de 1885, sabemos que Ancud contaba con 3.825 casas, 418 ranchos y 122 cuartos; mientras que Castro tenía 5.620 casas, 914 ranchos y 21 cuartos; y Quinchao 1.835 casas, 512 ranchos y 9 cuartos, como se registraba en el Censo de población de 1886. La preponderancia de Castro no implicaba que hubiese un mayor desarrollo de la infraestructura urbana, como se comprenderá. A comienzos del siglo XX, y a pesar del crecimiento económico que había experimentado Ancud producto del comercio maderero, las impresiones que provocaba no eran de las mejores. Al decir del inspector de colonización Alfredo Weber, cuando una persona desembarcaba en dicho puerto, aún

"con la impresión de la hermosísima entrada a la bahía que acababa de contemplar, i viva aun en su memoria la admiración que le han causado las florecientes industrias, la vida robusta i moderna de las jóvenes ciudades vecinas, Punta Arenas, Puerto Montt o Valdivia; se [sentía] profundamente desilusionado al observar, a dos pasos del muelle, una dársena mugrienta, depósito de basuras, i sentados en filas, sobre las piedras mohosas, algunas docenas de holgazanes, mudos, descalzos, harapientos; i a su lado otra fila compacta de jotes, tan indiferentes i apáticos como aquellos, i mas alla algun grupo de mendigos en toda su asquerosa indijencia. A poca distancia del muelle cesan ya todas las señales de comercio o se presentan a las puertas los dueños de pobres i escasos despachos" (1903, p. 134).

En las islas al interior del archipiélago el panorama no había variado, en esencia, desde la administración española. Allí vivían pequeños grupos de aborígenes en estrecho contacto con las playas, pues obtenían su sustento más del mar que de la tierra. No había ciudades y ni siquiera aldeas, salvo 
nombres sobre un mapa que intentaban definir un sector que en alguna eventualidad, como la llegada de misioneros o una fiesta religiosa, concentraba grupos humanos de manera coyuntural, pero que pasado el momento volvía a quedar deshabitado, regresando los pobladores a sus respectivos $y$ dispersos hogares. Como no existían almacenes ni tiendas de aprovisionamiento, el comercio debía hacerse en bote a la Isla Grande o al continente. La visión más característica de tales caseríos era la que mostraba un paisaje saturado de vegetación con un pequeño claro donde se emplazaba una iglesia, una escuela y una o dos residencias, cada una rodeada por una tranquera. Los indígenas vivían en estas condiciones, como lo registraba García Huidobro:

"en casitas aisladas a orillas del mar o en los potreros, donde ordeñan sus ganados de vacas i ovejas para comerciar la leche en Ancud. Allí en sus casas se dedican a cultivar el terreno con arvejas i papas, i después rodeados de su familia i alrededor del fuego, se trasmiten todas las tradiciones i supersticiones de encantos i brujerías con que han explotado su credulidad algunos de entre ellos que descollan en astusia i ociosidad [...] Para conocer a los isleños pobres, tratarlos en su miseria i verlos en su vida íntima, es necesario navegar el archipiélago; aquí los encontramos a cada paso, ya en el mar, ya en sus habitaciones en las costas, donde palpamos el último grado de la miseria en sus inmundos ranchos, i hasta en sus relaciones sociales. Allí vemos a los puercos, los perros i gatos en intima relación con ellos; parece que hicieran parte de su familia, porque los traen en sus viajes, i en su casa viven i habitan con ellos bajo el mismo techo i comparten tambien con ellos su alimento" (1864, p. 453 y 460).

El paso de las décadas no modificó la situación, el ayudante de la comisión encargada de explorar el archipiélago, encabezada por el capitán de fragata Roberto Maldonado, Aurelio Leguas, constataba a finales del siglo XIX la permanencia de este modo de vida, dependiente, en parte, de la tierra cultivable para lograr el sustento del hogar, pero fundamentalmente del mar para alimentarse $e$ intercambiar, a través del trueque, objetos $y$ provisiones. Su relato confirma que muchos de los lugares registrados en los mapas sólo tenían una concentración de población muy ocasional:

"La población, en su mayor parte, es ordinariamente propietaria de terrenos útiles para la labranza y ocupan sus heredades; esto hace que los pueblos sean pequeños y apenas una corta agrupación de casas se hallan ubicadas en contorno de la capilla, que los curas sólo visitan una o más veces al año, y de ordinario, para celebrar el santo de su advocación, lo que da lugar a cierta animación a la localidad, por la aglomeración de gentes del distrito y de otras capillas" (1897, p. 355).

Si las condiciones de vida eran duras para los chilotes, éstos tenían al menos la ventaja de conocer su entorno inmediato y las vías más expeditas de comunicación. Sin embargo, otro era el panorama para los colonos, quienes debían adaptar sus costumbres al escenario geográfico y humano que hemos descrito. En una publicación aparecida en 1899, Belisario García insistía en este tema, tratando de crear conciencia sobre el poco edificante futuro de los extranjeros en la Isla Grande:

"En cierta ocasión tuve oportunidad de visitar personalmente la casa de un colono residente en la parte denominada Mechaico ¡Qué grande no sería el asombro mío cuando conocí que la pobre familia, por guarecerse de los terribles azotes del invierno, había tenido necesidad de construir una especie de toldo dentro de la misma casa! El techo de la pobre casucha tenía innumerables goterones por todas partes i el patio i los alrededores de la pequeña finca no eran sino un pantano interminable. Aquella familia, en medio de una montaña, cuyos ecos parecían exhalar voces del otro mundo, asemejábase a espantajos que, teniendo horror invencible al bullicio, vivían a mil leguas de toda civilización i de todo trato racional con los habitantes del planeta" (1899, p. 372).

Arturo Whiteside llegaba a la misma conclusión, aunque recordaba que en tales circunstancias era evidente que "el chilote está mejor 
alojado que el huaso del norte a igualdad de clima; habita generalmente casas de madera bastante altas i bien ventiladas; el interior está divido en dos partes i a veces es sólo una pieza; en el primer caso una parte sirve de dormitorio i la otra es para el servicio general; en él viven los chanchos, los perros i las gallinas, en él se cocina, se come i se guardan los útiles de labranza i del menaje; rara vez hai chimenea i el hogar se encuentra en el centro del cuarto que pocas veces es entablado" (1900, p. 149). En este mismo sentido, se puede revisar a Vidal Gormaz (1875, p. 183-184).

Para fines de siglo, Francisco Javier Cavada describía a las casas campestres como viviendas compuestas por dos partes: la cocina, con su infaltable fogón, los monillos, el llagre, el hollín, el pozuelo, una caja o baúl donde se guardaba el trigo o la manteca; y la sala, que a la vez servía de salón, comedor y hasta de dormitorio; amoblada con una mesa sin barniz, unas cuantas sillas de madera, a las que inadecuadamente se les llamaba escaños, un piso cubierto de alfombras u otro tejido indígena, a cuyos extremos estaban arrolladas las camas que se extendían alli mismo por la noche, una alacena y un esquinero. Cavada agregaba que el "interior de las casas, generalmente sin pintar ni empapelar, ofrece un aspecto ahumado y renegrido por efecto de la acción constante del humo sobre el cielo, paredes y puertas. El exterior de las viviendas corresponde al interior" (1914, p. 131). En vez de ventanas de vidrio tenían tapas corredizas de madera, las que se mantenían abiertas con el propósito de recibir la luz. Sólo se cerraban en la noche o cuando soplaba el viento: "En cuanto a su vida íntima o de familia, el día lo dedican por entero a los menesteres de la casa y a los cuidados de la labranza, en la cual toman tanta parte y acaso más las mujeres que los hombres, y la noche a contarse cuentos, recitar corridos y proponer adivinanzas, todo esto al amor del fogón, no importándoles la espesa humareda, que bastaría acaso para asfixiar a un morador de la ciudad" (1914, p. 133). Estas pautas de vida, en términos generales, se proyectarian hasta el siglo siguiente, como bien lo describieron Schwarzenberg y Mutizábal (1926).

\section{CONCLUSIONES}

El recorrido que hemos realizado por la historia y cotidianeidad del archipiélago de Chiloé durante el siglo XIX, constituye un acercamiento a su diversidad y a la identidad que ha hecho célebre a esta zona de Chile desde hace décadas. Más allá de la imagen construida para generar un interés comercial hacia esta realidad insular, podemos percatarnos de que la vida chilota, tanto en los centros poblados como en los campos y caletas, estuvo marcada por penurias, privaciones y bastantes calamidades que, sin duda, marcaron y marcan la personalidad actual de no pocos chilotes. Esas pautas de vida moldeadas por la geografía, el aislamiento que experimentó Chiloé durante siglos y el mestizaje racial y cultural; fueron elementos potenciados y precisados en el período que aquí hemos abordado. Pero las identidades no sólo se construyen mirándose al espejo, sino también recogiendo las opiniones de otros como lo ha indicado Todorov (1993). De hecho, las referencias al archipiélago y a los chilotes fueron de diversa naturaleza. Desde aquellas que destacaban las virtudes del entorno y de los pobladores hasta las que entregaban un balance negativo respecto de un estilo de vida tachado de atrasado y bárbaro, percepciones que lamentablemente se proyectaron también hasta avanzado el siglo XX y que no se modificarían hasta que el uso de la tecnología permitiera mejorar las comunicaciones terrestres y marítimas y reformar dicho estilo de vida.

Nuestro primer siglo republicano entregó a las autoridades y a los habitantes de este mundo insular no sólo la acentuación de muchas características que venían del período colonial, sino también redefinió el día a día a través de una nueva estructura administrativa que buscó impulsar el comercio, las comunicaciones y la colonización. No obstante este esfuerzo, fueron las singularidades de esta geografía insular las que finalmente siguieron determinando el modo de vida, el hábitat y, en concreto, la identidad de los chilotes. Dicha relación recíproca entre la geografía y los chilotes fue evidenciada tanto por las descripciones de viajeros y como de funcionarios estatales, haciendo notar las obligadas adaptaciones de pobladores y colonos, como también de los centros poblados y las viviendas. Lo apuntado no significa que consideremos que esta sea la única dimensión que defina una idiosincrasia ni los problemas locales, lo cual pecaría de reduccionismo, pero sin duda no es un aspecto menor 
al momento de comprender la realidad insular y creemos que no se le ha ponderado lo suficiente cuando se busca abordar las peculiaridades de la compleja vida económica, social y cultural que tomó lugar dentro de una provincia, aún percibida por las autoridades de la capital y muchos chilenos, como extraña y ajena a principios del nuevo siglo.

\section{BIBLIOGRAFÍA}

"Provincia de Chiloé" (1876), en Oficina Central de Estadísticas. Quinto Censo Jeneral de la población de Chile, levantado el 19 de abril de 1875, Valparaíso: Imprenta del Mercurio.

Barrientos, P. J. (1997) [1948]. Historia de Chiloé. Santiago: Editorial Andujar,

Carreño Palma, L. (1997). "Chilotes en Aysén y explotación de los recursos naturales", en Boletín de Historia y Geografía, 13, 93-102.

Casanueva, F. (1992). "Chiloé, el jardín de la Iglesia (Notas para la historia de una evangelización colonial lograda)", en Europa e Iberoamérica: Cinco siglos de intercambios. Vol. II. IX Congreso Internacional de Historia de América, Sevilla, 7-31.

Cavada C., D. (1945). "Última jornada”. Anales de la Universidad de Chile (AUCh), 57 y 58, 195-229.

Cavada, D. (1926). Centenario de Chiloé, 1826-1926. Tipos, bosquejos y leyendas insulares, Los Ángeles: Imprenta Gutemberg.

Cavada, F. J. (1914). Chiloé y los chilotes. Ensayos de folklore y lingüística de la provincia de Chiloé. Santiago: Imprenta Universitaria.

Cuadra, P. L. (1866). "Bosquejo jeográfico de Chiloé", AUCh, XVIII, 266-276.

Darwin en Chile (1832-1835) (1995). Viaje de un naturalista alrededor del mundo por Charles Darwin. Santiago: Editorial Universitaria.

Emperaire, J. (2002) [1963]. Los nómades del mar. Santiago: LOM Ediciones.

Espinoza, E. (1897). Jeografía descriptiva de la República de Chile, Santiago: Imprenta i Encuadernación Barcelona.

Fesun, N. (2000). "De las notas sobre la navegación alrededor del mundo en la lancha Morzh", en Carmen Norambuena y Olga Uliánova (compilación, estudios introductorios y notas). Viajeros rusos al sur del mundo. DIBAM-USACH. Santiago: Instituto de Estudios Avanzados-Centro de Investigaciones Diego Barros Arana. Colección Fuentes para la Historia de la República. XV, 423-424.
Fraile, P. \& Bonastra, Q. (2001). Modelar para gobernar. El control de la población y el territorio en Europa y Canadá. Una perspectiva histórica. Barcelona: Publicacions de la Universitát de Barcelona.

García Huidobro, C. (1864). "Provincias meridionales de Chile. Su descripción según viaje hecho a ellas por don Carlos García Huidobro", en Anales de la Universidad de Chile (AUCh), tomo XXV, 439-489.

García, B. (1899). "Chile como país colonizador", La Revista de Chile. III, 11, 343-344.

Gilchrist, D. (1981). Chiloé, paraíso de viento y lluvia. Santiago: Editorial Nascimento.

González de Agüeros, P. (1988). Descripción historial de Chiloé (1791). Santiago: Instituto de investigación del patrimonio territorial de Chile. Universidad de Santiago de Chile.

Guarda, G. (2002). Los encomenderos de Chiloé. Santiago: Ediciones de la Universidad Católica de Chile.

Juliet, C. (1871). "Esploración científica practicada por orden del Supremo Gobierno i según las instrucciones del doctor don R. A. Philippi, por don Carlos Juliet, ayudante de la comisión esploradora del mar i costas de Chiloé i Llanquihue, a bordo del "Covadonga", en AUCh, t. XXXIX, 81-168.

Larrocau, M., A. (2000). Queilen: 300 años de historia. Tesis para optar al grado de Licenciado en Historia. Santiago: Instituto de Historia. Pontificia Universidad Católica de Chile.

Lowenthal, D. (1998). El pasado es un país extraño. Madrid: Akal.

Maldonado C., R. (1897). Estudios geográficos e hidrográficos sobre Chiloé. Santiago: Establecimiento Poligráfico "Roma".

Mansilla T., S. (Presentador) (2008). ¿Adónde se fue mi gente? Memorias y realidades en la construcción de Chiloé (s. XVI al XXI). Osorno: Editorial Universidad de Los Lagos.

Mansilla, J. D. (2005). "Exploraciones hidrográficas inglesas en el archipiélago de Chiloé”, en Charles Darwin en Chiloé y Aysén. Calbuco: Ediciones Caicaén.

Martin, C. (1881). "Apuntes geográficos sobre el interior de Chiloé". Revista de Chile, I, 75-95.

Martinic, M. (2005). De la trapananda al Aysen. Una mirada reflexiva sobre el acontecer de la región de Aysén desde la Prehistoria hasta nuestros días. Santiago: Pehuén editores.

Mc Bride, J. M. (1938). Chile: su tierra y su gente. Santiago: Prensas de la Universidad de Chile.

Montiel V., D. (2002). Crónicas de un mundo insular. Ancud: 
Dimar ediciones.

Pérez Rosales, V. (1986) [1857] Ensayo sobre Chile. Santiago: Ediciones de la Universidad de Chile.

Sagredo Baeza, R. \& González L., J. I. (2004). La Expedición Malaspina en la frontera austral del imperio español. Santiago: Editorial Universitaria-Centro de investigaciones Diego Barros Arana.

Schwarzenberg, J. \& Mutizábal, A. (1926). Monografía geográfica e histórica del Archipiélago de Chiloé. Concepción: Wissenschacfliches Archiv von Chile.

Todorov, T. (1993). "El viaje y su relato", en Las morales de la historia. Barcelona: Paidós.

Urbina Burgos, R. (1983). La periferia meridional indiana: Chiloé en el siglo XVIII. Valparaíso: Ediciones Universitarias de Valparaíso.

Urbina Burgos, R. (2002). La vida en Chiloé en los tiempos del fogón, 1900-1940. Valparaíso: Ediciones Universidad de Playa Ancha.

Urbina Burgos, R. (2010). El municipio y la ciudad de Castro. La corporación edilicia en la reconstrucción de la ciudad. Desde el incendio de 1936 hasta el sismo de 1960. Concepción: Editorial Okeldán.

Urbina, M. X. (2011). "Análisis histórico cultural del alerce en la Patagonia Septentrional Occidental. Chiloé, siglos XVI al XIX", en Magallania, 39(2), 57-73.

Vázquez de Acuña, I. (1991-1992). "Evolución de la población de Chiloé (siglos XVI- XX)", en Boletín de la Academia Chilena de la Historia (BAChH), 102, 403-457.

Vega, N. (1896). "Memoria del ajente jeneral de colonización en Europa correspondiente a 1896". Santiago: Anexo a la Memoria del Ministerio de Colonización y Culto.

Vidal Gormaz, F. (1875). "Reconocimiento del Río Maullín por la comisión esploradora de Chiloé i Llanquihue, bajo la dirección del capitán graduado de fragata...". Anuario Hidrográfico de la Marina de Chile (AHMCh), I, 183-184.

Weber, A. (1903). Chiloé, Su estado actual, su colonización y su porvenir, Santiago: Imprenta Mejía.

Westhoff, F. (1867). "Memoria del subdelegado marítimo de los archipiélagos de los Chonos o Guaitecas". AUCh, t. XXIX, 445-474.

Whiteside, A. (1900). "Chiloé i sus colonias", La Revista de Chile. IV, 43, 106-112. 